\title{
Granulocytic ehrlichiosis: an emerging or rediscovered tick-borne disease?
}

\author{
N. H. OGDEN, Z. WOLDEHIWET* and C. A. HART $\dagger$ \\ Departments of Veterinary Clinical Science and Animal Husbandry, * Veterinary Pathology and $†$ Medical \\ Microbiology and Genito-Urinary Medicine, Centre for Comparative Infectious Diseases, University of \\ Liverpool, PO Box 147, Liverpool L69 3GA
}

\begin{abstract}
The Ehrlichieae are gram-negative obligately intracellular bacterial pathogens. They can be divided into at least three genogroups on the basis of 16S rRNA gene sequences, but are also classified by target cell specificity. A group of granulocytic ehrlichiae primarily infect neutrophils and fall into genogroup II. The granulocytic ehrlichiae are subdivided by their target hosts, i.e., Ehrlichia phagocytophila in cattle and sheep, $E$. equi in horses, and the agents of human (HGE) and llama (LGE) granulocytic ehrlichioses. However, these subdivisions may give a false impression, as all these species are closely related both antigenically and on the basis of 16S rRNA operon sequence. In addition, crossspecies transmission can occur naturally or by experimental infection. The vectors for these granulocytic ehrlichiae are hard-bodied ixodid ticks, and the reservoir hosts are probably wild rodents, deer and sheep. In each host, this illness presents as a febrile disease which can be followed by immunosuppression leading to secondary infections.
\end{abstract}

\section{Introduction}

Members of the genus Ehrlichia have long been recognised as tick-borne, veterinary pathogens, but the recent emergence of two 'new' human pathogens, E. chaffeensis and the agent of human granulocytic ehrlichiosis (HGE), has rekindled interest in these organisms [1-3]. Clinical HGE infections occur in the USA and mainland Europe, and the causal organism belongs to the Ehrlichia genogroup II known as the granulocytic ehrlichiae. One member of this group, $E$. (Cytoecetes) phagocytophila, is common and widespread in the UK and mainland Europe. E. phagocytophila is closely related to or conspecific with the HGE agent, so considerable potential exists for human granulocytic ehrlichia infections to occur in the UK. Despite the widespread occurrence of the agents of granulocytic ehrlichioses - particularly E. phagocytophila whose importance as the causal agent of tickborne fever (TBF) in domestic ruminants has been recognised for many decades - knowledge of these organisms and their epidemiology is rudimentary. Consequently, there is a renewed need for studies on the host associations, epidemiology and taxonomy of the granulocytic ehrlichiae and this article reviews current knowledge of these organisms as a basis for such studies.

Received 24 Nov. 1997; accepted 14 Jan. 1998.

Corresponding author: Professor C. A. Hart.

\section{Taxonomy}

The genus Ehrlichia, named in 1945 in honour of Paul Ehrlich, comprises obligately intracellular, gram-negative bacteria which are classified in the $\alpha$-subgroup of Protobacteria on the basis of sequence analysis of $16 \mathrm{~S}$ rRNA genes [2-6]. Such sequence analysis differentiates the Ehrlichieae from the Rickettsiae and splits the Ehrlichieae into at least three genogroups (Table 1) [721]. The types of circulatory leucocytes targeted by each Ehrlichia species correspond, to some -degree, with their genogroup. The major cellular targets of the ehrlichiae of genogroup I (e.g., E. canis, E. chaffenesis) and genogroup III (e.g., E. risticii, E. sennetsu) are monocytes and macrophages. Most species of genogroup II (e.g., E. phagocytophila, E. equi and the HGE agent) multiply mainly in neutrophils; those that do so are known as the 'granulocytic ehrlichiae' and the diseases they cause are called the granulocytic ehrlichioses.

The granulocytic ehrlichiae of the temperate zone infect domestic and wild animals and man, and are transmitted by hard-bodied (ixodid) tick vectors. Their widespread distribution in the USA, mainland Europe and the UK follows the geographic distribution of their vectors. E. phagocytophila was the first to be discovered, almost by accident, in 1932 [22]. This was followed by $E$. (Cytoecetes) microti in 1938, E. equi in 1969 [12], the HGE agent in 1994 [3] and, most 


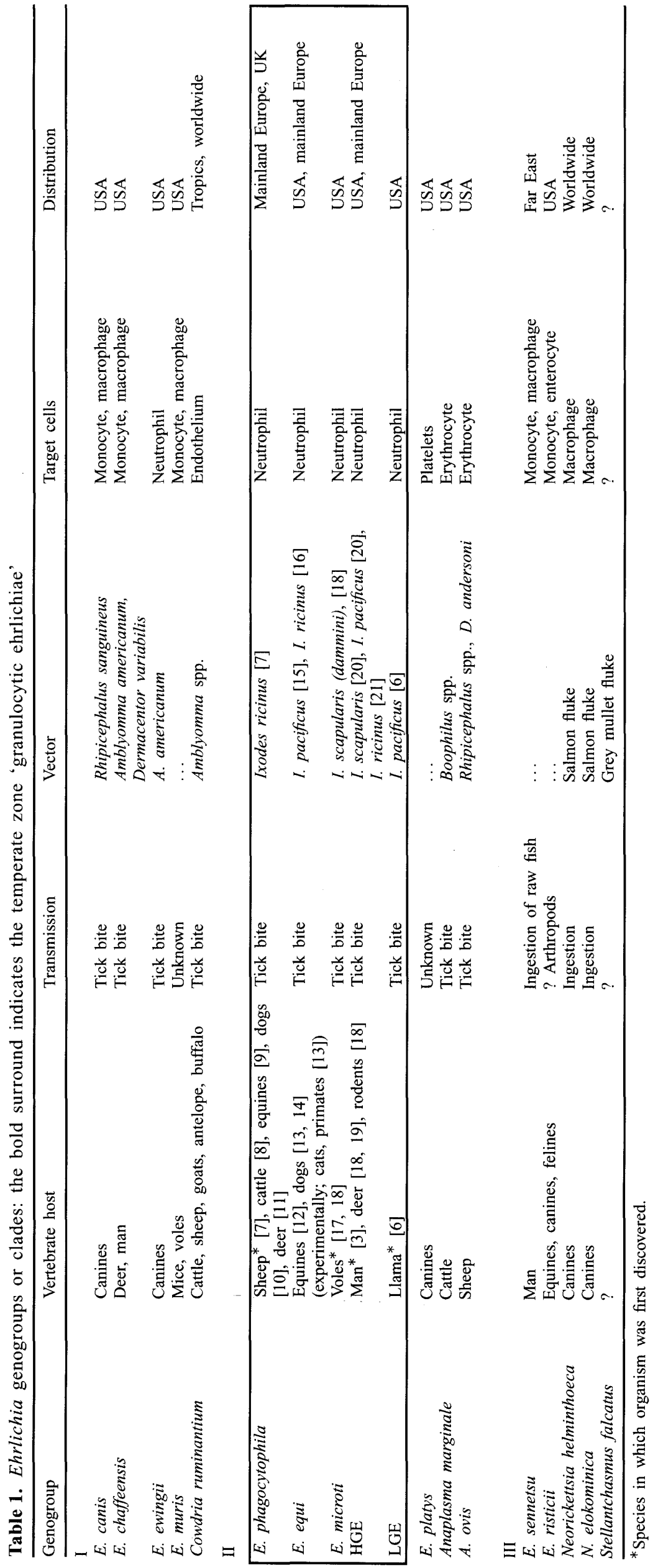


recently, the agent of llama granulocytic ehrlichiosis (LGE) in 1997 [6]. Within the granulocytic Ehrlichia genogroup, temperate species have been named according to the vertebrate host in which they were first, or are commonly found (Table 1). However, a number of factors suggest strongly that such a classification may be misleading, and that these granulocytic ehrlichiae may even be the same species. Studies in Europe and the USA have demonstrated consistently that only 2-3-bp differences occur (approaching 100\% homology) between the 1427-bp $16 \mathrm{~S}$ rRNA sequences of $E$. phagocytophila, E. equi and the agents of HGE and LGE [2, 6, 14, 23, 24]. Furthermore, nucleotide sequences of the groESL heat shock operon of E. phagocytophila, E. equi and the HGE agent show 99-99.9\% homology, with the deduced amino-acid sequences being identical [25]. What such small differences mean in terms of the vertebrate host associations of the granulocytic ehrlichiae is unclear. The 16S rRNA sequences of granulocytic ehrlichiae isolated from two different Swedish cattle (both thus 'classified' as E. phagocytophila) showed the same small degree of difference as that between 16S rRNA sequences of European isolates of E. phagocytophila and the HGE agent from the USA [23]. The biological behaviour of the granulocytic Ehrlichia 'species' is also remarkably similar in a number of respects. All appear to be transmissible to a wide, and similar, range of vertebrate species in similar geographic regions (Table 1). Experimental infections between species result in similar clinical consequences. For example, the HGE agent causes a clinical disease in horses that is indistinguishable from $E$. equi infection [26]. The HGE agent is serologically almost indistinguishable from E. phagocytophila and E. equi, the antigens of which are used to detect HGE in man [27, 28]. Furthermore, following recovery from experimental HGE infection, horses are protected against further challenge by E. equi [26].

Although the granulocytic ehrlichiae may comprise a single species, or are at least indistinguishable on the basis of host association, strain variation certainly occurs. Isolates of E. phagocytophila from cattle and sheep in different geographic foci of infection within the same country vary considerably with regard to their virulence and ability to cross-protect $[29,30]$. Antigenic variation has been observed also in isolates of the HGE agent [31]. Clearly, further studies are required to investigate the taxonomy of the granulocytic ehrlichiae and how this relates to their antigenic heterogeneity, virulence and vertebrate host associations.

\section{The vector}

The ixodid (hard-bodied) tick Ixodes ricinus is the vector of E. phagocytophila, and is likely to be the vector of $E$. equi and HGE in Europe [7, 16, 21]. In central and eastern USA, I. scapularis is the vector of HGE and, in the west, I. pacificus is the vector of $E$. equi [20]. All these tick species will feed on almost any terrestrial vertebrate, which is why they are important vectors of tick-borne zoonoses in Europe (including the UK) and the USA [32]. The ticks have three feeding stages (larva, nymph and adult) which are parasitic only for short periods. Each stage feeds once only, for 3-14 days, and then randomly drops off the host into the herbage litter layer. Here they moult to the next developmental stage and may remain for up to 1 year before becoming active, whereupon they ascend the herbage to wait for another host and their next meal.

In order to transmit infection from one host to another, granulocytic ehrlichiae must survive in the tick through the moulting process (known as transstadial transmission). E. phagocytophila is maintained trans-stadially, and ticks acquiring infection as larvae may be infective as both nymphs and adults [7]. Vertical transmission from an adult female to her offspring larvae (transovarial transmission) occurs in some tick-transmitted infections, but such transmission of E. phagocytophila either does not occur or does so only with low efficiency $[7,33]$. The development and growth of granulocytic ehrlichiae in the vector has not been studied, but it is likely that, as with other tickborne rickettsias, multiplication occurs within a number of tissues, including the salivary glands, and that the organism is transmitted to the vertebrate host in the saliva of the feeding tick [34]. Some processing of the organism within the tick may have to occur during feeding before the organism becomes infective, because macerates of infected, unfed ticks are not infective to sheep, whereas those prepared from ticks that have been allowed to partially feed on an uninfected host are infective [33].

The risk of infection to man and domestic animals depends on what proportion of questing ticks in a particular focus are infected and on the density of actively questing ticks. The density of active ticks is a function of their seasonal activity. For example, in upland regions of the UK, the main peak of I. ricinus tick activity occurs in spring and early summer, with a lesser peak in autumn, while ticks in woodlands may quest continuously, reaching a peak of activity in midsummer [35]. Consequently, animal and, if they occur in the UK, human infections are most likely to present to clinicians during these peaks of tick activity.

\section{Reservoirs}

The question of which species are the most important reservoirs of the granulocytic ehrlichiae remains unresolved. The tick vectors will feed on almost any terrestrial vertebrate, which explains why a single 
granulocytic Ehrlichia species can cause infections in a diverse range of vertebrate species. However, for an infected animal to be a 'competent' reservoir requires that it then transmits infection to uninfected ticks which maintain the infection trans-stadially and, subsequently, infect another vertebrate. So far, only sheep have been conclusively demonstrated to be 'competent' reservoirs [7], but any species that can be infected with granulocytic ehrlichiae could be a potential competent reservoir. The importance of any one reservoir species in maintaining endemic cycles of granulocytic ehrlichia infection depends on the proportion of ticks that feed on that species. In woodlands, the natural habitat for $I$. ricinus and $I$. scapularis, a wide variety of wild mammals and birds feed and maintain the ticks. Deer are important hosts of ticks in woodlands and may be reservoirs of E. phagocytophila and the HGE agent $[11,19]$. Wild woodland rodents also feed many ticks and, even though laboratory rodents are resistant to granulocytic ehrlichia infection $[29,36]$, their wild cousins may be important reservoirs [18]. Studies in our laboratory suggest that cycles of $E$. phagocytophila infection are maintained in UK woodlands by wild species. However, by increasing the density of domestic livestock, man's influence can result in these species becoming the dominant tick hosts. Sheep on many UK uplands host nearly all $I$. ricinus ticks of all three feeding stages [37] and, being competent reservoirs, are likely to be crucial to maintenance of $E$. phagocytophila in these habitats.

In contrast, dogs, well-groomed horses kept for recreation and man are unlikely to be important reservoirs because they occur at low densities in the countryside and feed few ticks. Any ticks that do attach to these hosts are unlikely to survive to find and infect another susceptible host. For these reasons, man, dogs, recreational horses and, possibly, pet llamas in California [6] are most likely to acquire granulocytic ehrlichia infections by accident from ticks that became infected while feeding on wild species or domestic livestock.

Transmission efficiencies have not been quantified from either vertebrate host to tick, or tick to host, but it may take only one E. phagocytophila-infected $I$. ricinus tick to provide a sufficient infective dose to produce clinical disease (i.e., TBF) in a naïve sheep [33]. Following infection, sheep remain infective to ticks for at least 35 days, and possibly as long as 2 years, so a high prevalence of infection in questing nymphal and adult ticks could be expected in UK uplands. Indeed, the probability that a susceptible sheep will acquire infection on tick-infested pasture is probably $100 \%$ - a feature recognised by farmers of tick-infected UK uplands who will only buy sheep that have been exposed previously to ticks and are likely to have some immunity to clinical TBF. The consequences of failing to observe this precaution can be catastrophic, as demonstrated when 225 (91\%) of 280 naïve, pregnant sheep aborted, because of $E$. phagocytophila infection, within 4 weeks of introduction to $I$. ricinus-infested pasture [38], including $25 \%$ of these animals that aborted within 9 days of introduction to the pasture.

\section{Artificial culture}

Only recently has pure growth of the granulocytic ehrlichiae been achieved in artificial culture. E. equi and the HGE agent have both been grown in the human promyelocytic leukaemia cell line HL60 [39], where both form similar intravacuolar microcolonies (morulae) that differ greatly from those formed by ehrlichiae of other genogroups [40]. E. equi has been cultured in a tick-cell line [41]. It remains to be seen whether $E$. phagocytophila may be cultured similarly. To date, infected sheep have been the main source of this bacterium.

\section{Pathogenesis and pathology}

To choose to grow in a professional phagocyte such as the polymorphonuclear neutrophil is analogous to putting one's head in a lion's mouth to scavenge food from between its teeth. This problem is compounded by the short $(6-12 \mathrm{~h})$ life-span of the neutrophil.

Most of our understanding of the pathogenesis of the granulocytic ehrlichioses is based on studies of $E$. phagocytophila infection of sheep, which does, however, display some marked similarities to HGE infection in man. Following experimental inoculation or feeding of an infected tick, E. phagocytophila can be detected microscopically in circulating leucocytes after 3 days. However, blood is infective to other sheep within $24 \mathrm{~h}$ of inoculation [42]. Cytoplasmic inclusions appear first in eosinophils, then neutrophils, and finally monocytes, over a period of 7 days, and inclusions may be detected in neutrophils for 2-3 weeks after infection [43]. E. phagocytophila enters and multiplies in polymorphonuclear cells of the peripheral circulation [44] but, following experimental infection, has also been detected in alveolar macrophages and Kupffer cells [45]. E. phagocytophila enters host cells by endocytosis and is found within endocytic vacuoles [46] containing one or more organisms (Fig. 1). Larger inclusions which contain dividing bacteria are called morulae (Fig. 2). It appears that there is inhibition of phagolysosome fusion (unpublished observations); thus the bacteria may not be exposed to lysosomal enzymes and may also evade the neutrophil's oxidative burst. Similar changes and inclusions have been described for $E$. equi and HGE infections [40]. The bacteria are released from neutrophils by unknown mechanisms, but they may be found in the plasma of infected sheep, which is in turn infective [47]. Granulocytic 


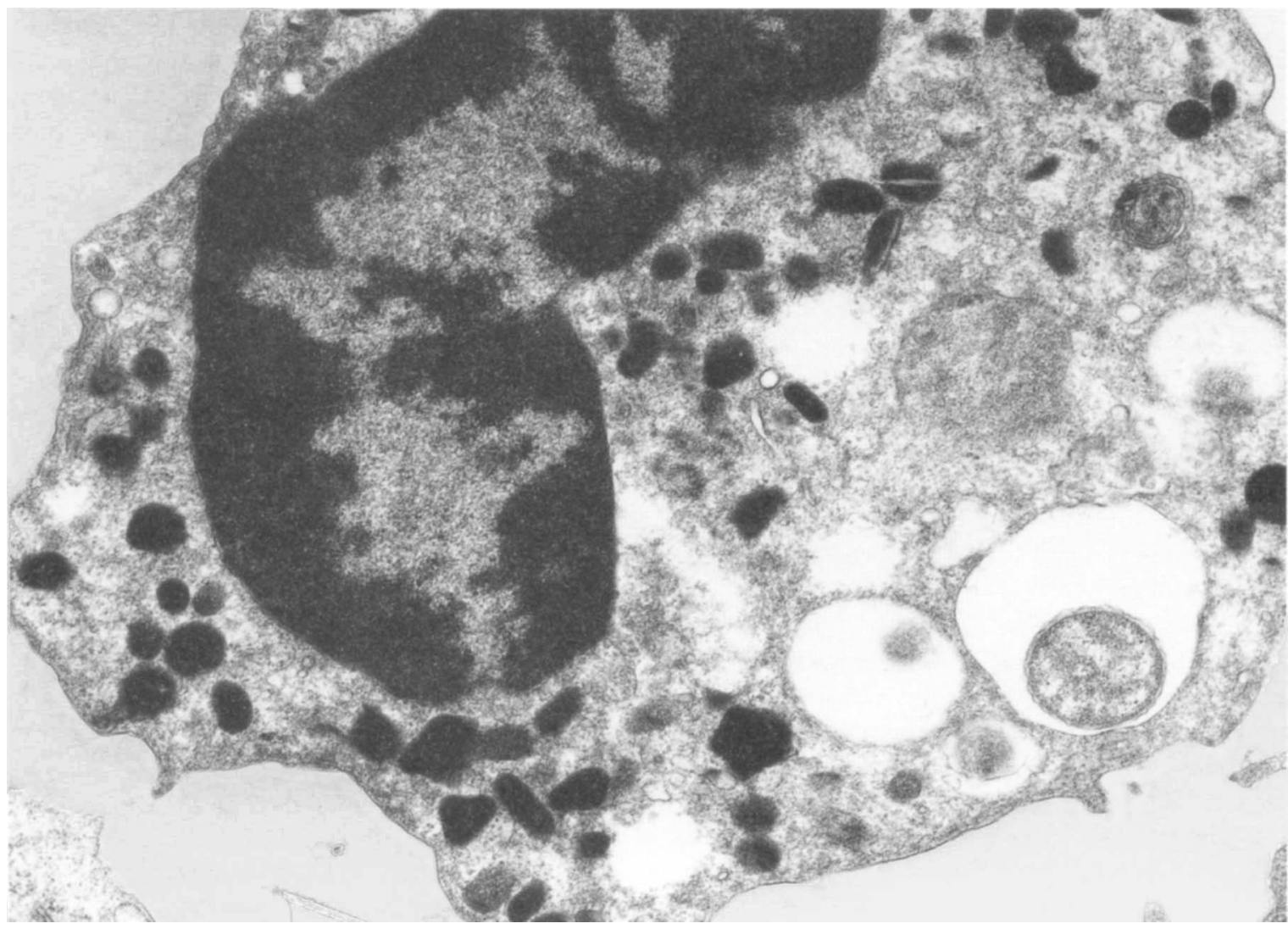

Fig. 1. Thin-section electronmicrograph of an ovine neutrophil showing an endocytotic vacuole containing E. phagocytophila.

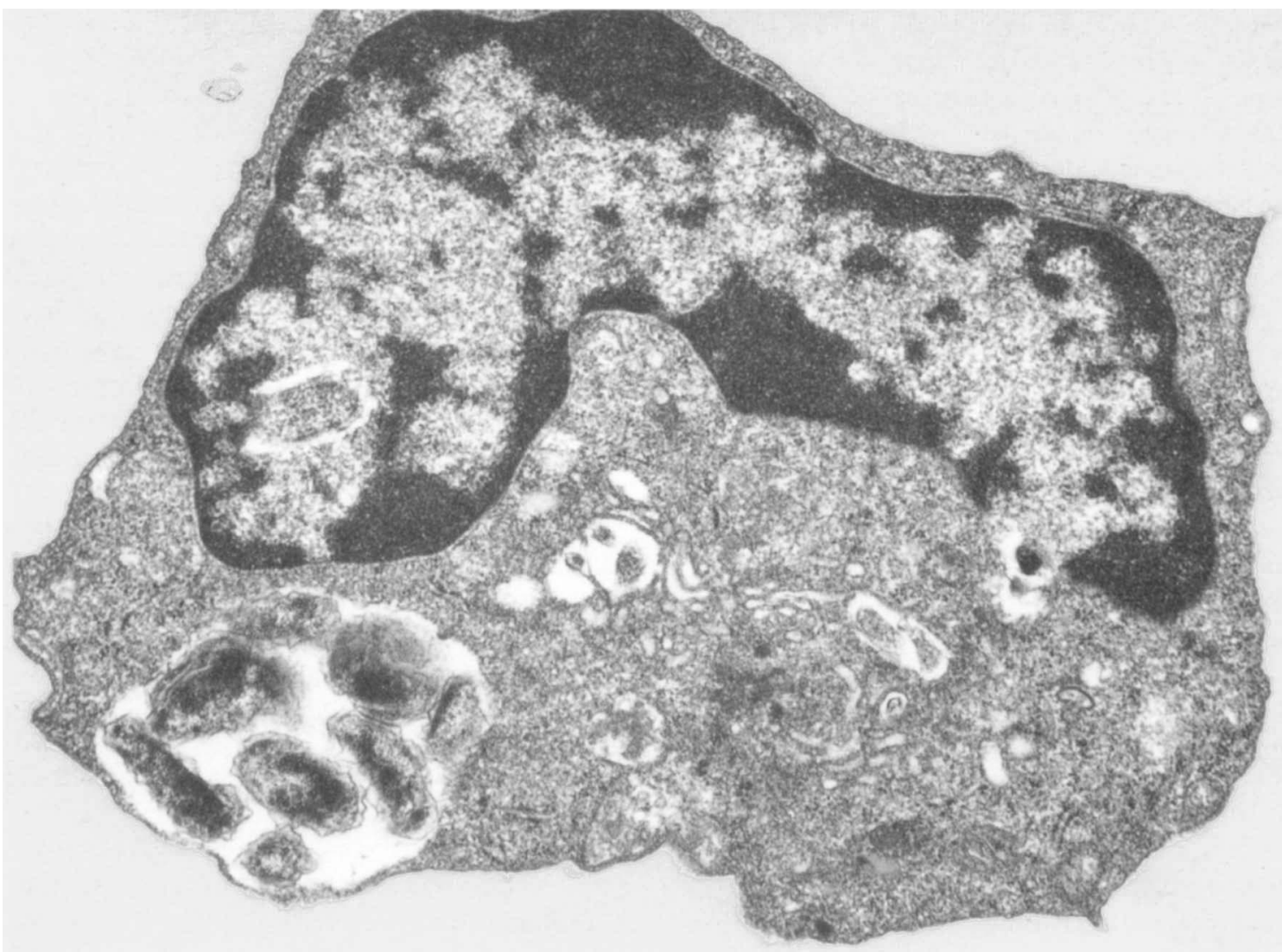

Fig. 2. Thin-section electronmicrograph of an ovine neutrophil containing growing E. phagocytophila within an endocytotic vacuole (morula). 
ehrlichioses in all species are accompanied by pyrexia and immunosuppression. TBF in sheep is characterised by severe leucopenia associated with early lymphocytopenia (of B lymphocytes and CD4+, CD8+, but not $\gamma-\delta \mathrm{T}$ lymphocytes) and prolonged neutropenia that compromises the immune response. In addition, lymphocytes of infected sheep have reduced responses to mitogens, and neutrophil attachment, phagocytosis and killing are inhibited [48-50]. Granulocytic ehrlichiae may also infect thrombocyte precursors in bone marrow, as thrombocytopenia has been observed in $E$. phagocytophila, E. equi and HGE infections $[28,51,52]$. In addition, granulocytic ehrlichiae may infect endothelial cells in horses [51].

\section{Clinical features}

There are striking similarities in the clinical features of the granulocytic ehrlichioses of domestic animals and man. Primary infections result in pyrexia and immunosuppression, which may render the host susceptible to more serious and potentially fatal secondary infections.

\section{Granulocytic ehrlichiosis in sheep and cattle}

Pyrexia is the first sign of infection and follows an incubation period of 3-4 days. It is maximal on the second day of parasitaemia, but the duration and magnitude vary between isolates of E. phagocytophila [53,54]. Affected animals are dull and anorexic, a rapid fall in milk production occurs in dairy cattle and, if pregnant, cattle and sheep usually abort $[55,56]$. Infertility associated with spermatopenia and abnormalities of spermatozoa occurs in infected males [57]. The most important clinical consequences are a result of secondary infections, the most common of which in sheep is 'tick pyaemia' caused by secondary staphylococcal septicaemia. Multiple abscesses develop in almost any tissue, resulting in ill-thrift, crippling lameness and death. An estimated 300000 lambs suffer tick pyaemia every year in UK uplands, which represents $1 \%$ of the total UK sheep flock [58]. $E$. phagocytophila infection renders both cattle and sheep more susceptible to respiratory tract infections with Pasteurella spp. and Chlamydia psittaci [54]. Sheep are rendered susceptible to clostridial diseases and the pathogenicity of the tick-borne flavivirus causing 'louping ill' is enhanced. Cattle may be rendered susceptible to Johnes disease (caused by Mycobacterium paratuberculosis) and to listeriosis [54].

\section{Granulocytic ehrlichiosis in man}

Most described cases have occurred in Wisconsin and Minnesota, USA [28], but human infection has been detected in Slovenia [24] and Sweden [59]. Following an infective tick bite, an incubation period of 1-60 days (median 8 days) elapses before the onset of pyrexia (mean $39.3^{\circ} \mathrm{C}$ ). Accompanying symptoms include myalgia, headache, nausea, rigors and arthralgia, but infection with granulocytic ehrlichiae alone may be short-lived and self limiting $[24,28]$. In one study of 41 affected patients, $23 \%$ were hospitalised and three were admitted to intensive care, of whom two later died. Twelve patients suffered respiratory symptoms, some with radiographically detectable pneumonia. Both patients who died suffered opportunist or secondary infections; Candida albicans pneumonia, Cryptococcus neoformans pneumonia and gastro-oesophageal haemorrhage caused by herpes simplex virus 1 and $C$. albicans [28]. HGE has, thus far, been diagnosed more frequently in males, those aged $>40$ years, and those with regular contact with animals [28]. Recent evidence suggests that patients infected with the HGE agent may frequently be co-infected with the tick-borne pathogens Borrelia burgdorferi s.1. (the Lyme disease spirochaete) and Babesia microti. HGE may alter or enhance the pathogenicity of these infections [60].

\section{Granulocytic ehrlichiosis in horses and llamas}

Subclinical infection or infection accompanied by mild clinical signs may be the most frequent outcome of infection in horses. The prevalence of anti-E. equi antibodies far outweighs that of detected clinical disease [61]. Clinically affected equines and llamas are pyrexic and show vague symptoms of depression, anorexia and slight hind-limb ataxia [6,9,51]. Some horses develop limb oedema and cardiac arrhythmias associated with vasculitis, but most recover within $7-$ 14 days [51].

\section{Diagnosis and treatment}

HGE should be considered as a differential diagnosis for previously healthy individuals who present with 'flu-like' symptoms following outdoor activity in the USA or mainland Europe where they may have been exposed to tick bites. It may also be advisable to consider HGE as a possible cause of similar symptoms in patients with a history of tick bite in the UK. Diagnostic adjuncts include peripheral white blood and platelet counts, the demonstration of morulae in neutrophils and raised C-reactive protein [28]. Serological diagnosis is possible with $E$. equi or $E$. phagocytophila antigens $[27,28]$, but definitive diagnosis is by detection of granulocytic Ehrlichia $16 \mathrm{~S}$ rRNA gene DNA by a specific PCR $[2,3,6,14,23$, $24]$ or by direct culture $[39,41]$. Tetracycline or deoxycycline are the antimicrobial agents of choice and prolonged administration (up to 2 weeks) may be necessary to avoid relapses.

\section{Conclusions}

Although HGE has just emerged, as with most 'new' diseases this probably represents a lack of recognition 
rather than an entirely new disease. Clearly, the granulocytic ehrlichiae of wild and domestic animals have been present for many years, and it is likely that it is these infections which, via tick-borne transmission, result in HGE infections. The current taxonomy of the granulocytic ehrlichiae, based on the vertebrate species in which they were first discovered, is likely to be misleading because of the catholic feeding behaviour of the tick vectors. The granulocytic ehrlichiae may well all belong to the same species, yet variations between isolates do occur. How such variations may relate to adaptations to different reservoir host species, variations in virulence in domestic animals and man, and to different geographic distributions awaits a re-evaluation of their taxonomy. These bacteria also pose fascinating questions. How do they survive and multiply in phagocytic cells? Why does an organism with such a wide geographic distribution and a wide host range show a relative lack of genetic diversity? While answers to these questions are awaited, the granulocytic ehrlichiae continue to pose major health and welfare problems for domestic animals, affect food production and pose a risk to humans health.

\section{References}

1. Walker DH, Dumler JS. Emergence of the ehrlichioses in human health problems. Emerg Infect Dis 1996; 2: 18-29.

2. Anderson BE, Dawson JE, Jones DC, Wilson KH. Ehrlichia chaffeensis, a new species associated with human ehrlichiosis. J Clin Microbiol 1991; 19: 2838-2842.

3. Chen S-M, Dumler JS, Bakken JS, Walker DH. Identification of a granulocytotrophic Ehrlichia species as the etiologic agent of human disease. J Clin Microbiol 1994; 32: 589-595.

4. Anderson BE, Greene CE, Jones DA, Dawson JE. Ehrlichia ewingii sp. Nov, the etiologic agent of canine granulocytic ehrlichiosis. Int $J$ Syst Bacteriol 1992; 42: 299-302.

5. Wen B, Rikihisa Y, Mott J, Fuerst PA, Kawahara M, Suto C. Ehrlichia muris sp. Nov. identified on the basis of 16S rRNA base sequences and serological, morphological and biological characteristics. Int J Syst Bacteriol 1995; 45: 250-254.

6. Barlough JE, Madigan JE, Turoff DR, Clover JR, Shelley JM, Dumler IS. An Ehrlichia strain from a llama (Llama glama) and llama-associated ticks (Ixodes pacificus). J Clin Microbiol 1997; 35: 1005-1007.

7. MacLeod J, Gordon WS. Studies in tick-borne fever in sheep. I. Transmission by the tick Ixodes ricinus, with a description of the disease produced. Parasitology 1933; 25: 273-283.

8. Hudson JR. The recognition of tick-borne fever as a disease of cattle. Br Vet $J$ 1950; 106: 3-17.

9. Korbutiak E, Schneiders DH. First confirmed case of equine ehrlichiosis in Great Britain. Equine Vet Educ 1994; 6: 303-304.

10. Clark AM, Hopkins GF, MacLean IA. Tick-borne fever in dogs. Vet Rec 1996; 139: 268.

11. McDiarmid A. Modern trends in animal health and husbandry. Some infectious diseases of free-living wildlife. Br Vet $J 1965$; 121: $245-257$.

12. Gribble DH. Equine ehrlichiosis. J Am Vet Med Assoc 1969; 155: $462-469$.

13. Lewis GE, Huxsoll DL, Ristic M, Johnson AJ. Experimentally induced infection of dogs, cats, and nonhuman primates with Ehrlichia equi, etiologic agent of equine ehrlichiosis. Am J Vet Res 1975; 36: 85-88.

14. Johansson K-E, Pettersson B, Uhlen M, Gunnarsson A, Malmqvist $M$, Olsson E. Identification of the causative agent of granulocytic ehrlichiosis in Swedish dogs and horses by direct solid phase sequencing of PCR products from the $16 \mathrm{~S}$ rRNA gene. Res Vet Sci 1995; 58: 109-112.

15. Richter PJ, Kimsey RB, Madigan JE, Barlough JE, Dumler JS,
Brooks DL. Ixodes pacificus (Acari: Ixodidae) as a vector of Ehrlichia equi (Rickettsiales: Ehrlichieae). J Med Entomol 1996; 33: $1-5$.

16. Artursson K, Malmquist M, Olsson E, Bjöersdorff A, Eklund M, Gunnarsson A. Diagnositik av borrelios och granulocytar ehrlichios hos hast, hund och katt i Sveridge. Svensk Vet Tidn 1994; 46: $331-336$

17. Tyzzer EE. Cytoecetes microti N-G., N.S.P.,: a parasite developing in granulocytes and infective for small rodents. Parasitology 1938; 30: 242-257.

18. Telford SR, Dawson JE, Katavolos P, Warner CK, Kolbert CP Persing DH. Perpetuation of the agent of human granulocytic ehrlichiosis in a deer tick-rodent cycle. Proc Natl Acad Sci USA 1996; 93: 6209-6214.

19. Belongia EA, Reed KD, Mitchell PD et al. Prevalence of granulocytic Ehrlichia infection among white-tailed deer in Wisconsin. J Clin Microbiol 1997; 35: 1465-1468.

20. Dumler JS. Is human granulocytic ehrlichiosis a new Lyme disease? Review and comparison of clinical, laboratory, epidemiological, and some biological features. Clin Infect Dis 1997; 25 Suppl 1: S43-S47.

21. von Stedingk LV, Gürtelschmid M, Hanson HS et al. The human granulocytic ehrlichiosis (HGE) agent in Swedish ticks Clin Microbiol Infect 1998 (in press).

22. Gordon WS, Brownlee A, Wilson DR, MacLeod J. "Tick-borne fever". (A hitherto undescribed disease of sheep). J Comp Pathol 1932; 45: 301-312.

23. Engvall EO, Pettersson B, Persson M, Artursson K, Johansson K-E. A $16 \mathrm{~S}$ rRNA-based assay for detection and identification of granulocytic Ehrlichia species in dogs, horses and cattle. $J$ Clin Microbiol 1996; 34: 2170-2174.

24. Petrovec M, Furlan SL, Zupanc TA et al. Human disease in Europe caused by a granulocytic Ehrlichia species. J Clin Microbiol 1997; 35: 1556-1559.

25. Sumner JW, Nicholson WL, Massung RF. PCR amplification and comparison of nucleotide sequences from the groESL heat shock operon of Ehrlichia species. J Clin Microbiol 1997; 35: 2087-2092.

26. Barlough JE, Madigan JE, DeRock E, Dumler JS, Bakken JS. Protection against Ehrlichia equi is conferred by prior infection with the human granulocytotropic ehrlichia (HGE agent). $J$ Clin Microbiol 1995; 33: 3333-3334.

27. Dumler JS, Asanovich KM, Bakken JS, Richter P, Kimsey R, Madigan JE. Serological cross-reactions among Ehrlichia equi, Ehrlichia phagocytophila and human granulocytic ehrlichia. $J$ Clin Microbiol 1995; 33: 1098-1103.

28. Bakken JS, Krueth J, Wilson-Nordskog J, Tilden RL, Asanovich K, Dumler JS. Clinical and laboratory characteristics of human granulocytic ehrlichiosis. JAMA 1996; 275: 199-205.

29. Foggie A. Studies on the infectious agent of tick-borne fever in sheep. J Pathol Bacteriol 1951; 63: 1-15.

30. Tuomi J. Experimental studies on bovine tick-borne fever. (3) Immunological strain differences. Acta Pathol Microbiol Scand 1967; 71: 89-100.

31. Asanovich KM, Bakken JS, Madigan JE, Aguero-Rosenfeld M, Wormser GP, Dumler JS. Antigenic diversity of granulocytic Ehrlichia isolates from humans in Wisconsin and New York and a horse in California. J Infect Dis 1997; 176: 1029-1034.

32. Sonenshine DE. Ecology of non-nidicolous ticks. In: Biology of ticks, vol 2. New York, Oxford University Press. 1993: 3-65.

33. MacLeod J. Studies on tick-borne fever in sheep. II. Experiments on transmission and distribution of the disease. Parasitology 1936; 28: 320-329.

34. Smith RD, Sells DM, Stephenson EH, Ristic MR, Huxsoll DL. Development of Ehrlichia canis, causitive agent of canine ehrlichiosis, in the tick Rhipicephalus sanguineus and its differentiation from symbiotic Rickettsia. Am J Vet Res 1976; 37: $119-126$.

35. Gray JS. The development and seasonal activity of the tick Ixodes ricinus: a vector of Lyme borreliosis. Rev Med Vet Entomol 1991; 79: 323-333.

36. Tuomi J. Experimental studies on tick-borne fever. (1). Clinical and haematological data, some properties of the causative agent and homologous immunity. Acta Pathol Microbiol Scand 1967; 70: $429-445$.

37. Ogden NH, Nuttall PA, Randolph SE. Natural Lyme disease cycles maintained via sheep by co-feeding ticks. Parasitology 1997; 115: 591-599.

38. Jones GL, Davies IH. An ovine abortion storm caused by 
infection with Cytoecetes phagocytophila. Vet Rec 1995; 136: 127.

39. Goodman JL, Nelson C, Vitale B et al. Direct cultivation of the causative agent of human granulocytic ehrlichiosis. $N$ Engl $J$ Med 1996; 334: 209-215.

40. Popov VL, Han VC, Chen S-M et al. Ultrastructural differentiation of serogroups in the genus Ehrlichia. $J$ Med Microbiol 1998 47: 235-251.

41. Munderloh UG, Madigan JE, Dumler JS et al. Isolation of the equine granulocytic ehrlichiosis agent, Ehrlichia equi, in tick cell culture. J Clin Microbiol 1996; 34: 664-670.

42. Snodgrass DR. Studies on bovine petechial fever and ovine tick-borne fever. PhD Thesis, University of Edinburgh, 1974.

43. Woldehiwet $Z$. Observations on the immune responses of sheep infected with Cytoecetes phagocytophila. $\mathrm{PhD}$ Thesis, University of Edinburgh, 1981.

44. Woldehiwet Z, Scott GR. Corticosteroid therapy of tick-borne fever. Vet Rec 1982; 110: 151-152.

45. Munro R, Hunter AR, MacKenzie G, McMartin DA. Pulmonary lesions in sheep following experimental infection by Ehrlichia phagocytophila and Chlamydia psittaci. J Comp Pathol 1982; 92: 117-129.

46. Woldehiwet Z, Scott GR. Stages in the development of Cytoecetes phagocytophila, the causative agent of tick-borne fever. J Comp Pathol 1982; 92: 469-474.

47. Foggie A. Studies on tick pyaemia and tick-borne fever. Symp Zool Soc Lond 1962; 6: 51-58.

48. Woldehiwet Z. Depression of lymphocyte response to mitogens in sheep infected with tick-borne fever. J Comp Pathol 1987; 97: $637-643$.

49. Woldehiwet $Z$. The effects of tick-borne fever on some functions of polymorphonuclear cells of sheep. J Comp Pathol 1987; 97: 481-485.

50. Foster WNM, Cameron AE. Observations on the functional integrity of neutrophil leukocytes infected with tick-borne fever. J Comp Pathol 1970; 80: 487-491.

51. Madigan JE. Equine ehrlichiosis. In: Woldehiwet Z, Ristic M (eds) Rickettsial and chlamydial diseases of domestic animals. Oxford, Pergamon Press. 1993: 209-214.

52. Foster WNM, Cameron AE. Thrombocytopenia in sheep associated with experimental tick-borne fever infection. $J$ Comp Pathol 1968; 78: 251-254.

53. Tuomi J. Studies in epidemiology of bovine tick-borne fever in Finland and clinical description of field cases. Ann Med Exp Biol Fenn 1966; 44 Suppl 6: 1-62.

54. Woldehiwet Z, Scott GR. Tick-borne (pasture) fever. In: Woldehiwet $Z$, Ristic $M$ (eds) Rickettsial and chlamydial diseases of domestic animals. Oxford, Pergamon Press. 1993: 233-254.

55. Stamp JT, Watt JA. Tick-borne fever as a cause of abortion in sheep - part 1. Vet Rec 1950; 62: 465-468.

56. Wilson JC, Foggie A, Carmichael MA. Tick-borne fever as a cause of abortion and stillbirths in cattle. Vet Rec 1964; 76: 1081-1084.

57. Watson WA. Infertility in the ram associated with tick-borne fever. Vet Rec 1964; 76: 1131-1136.

58. Brodie TA, Holmes PH, Urquahart GM. Some aspects of tickborne infection of British sheep. Vet Rec 1986; 118: 415-418.

59. Dumler JS, Dotevall L, Gustafson R, Granström M. A population-based seroepidemiologic study of human granulocytic ehrlichiosis and Lyme borreliosis on the west coast of Sweden. J Infect Dis 1997; 175: 720-722.

60. Mitchell PD, Reed KD, Hofkes JM. Immunoserologic evidence of coinfection with Borrelia burgdorferi, Babesia microti, and Human Granulocytic Ehrlichia species in residents of Wisconsin and Minnesota. J Clin Microbiol 1996; 34: 724-727.

61. Madigan JE, Hietala S, Chalmers S, DeRock E. Seroepidemiologic survey of antibodies to Ehrlichia equi in horses in northern California. J Am Vet Med Assoc 1990; 196: $1962-1964$ 